\title{
PERBEDAAN EARNINGS MANAGEMENT BERDASARKAN PADA TAHAPAN LIFE CYCLE PERUSAHAAN YANG TERDAFTAR DI BEI
}

\author{
MI Mitha Dwi Restuti \\ Fakultas Ekonomika dan Bisnis, Universitas Kristen Satya Wacana Salatiga \\ mitha.restuti@staff.uksw.edu \\ Luluk Widyaningrum \\ Fakultas Ekonomika dan Bisnis, Universitas Kristen Satya Wacana Salatiga
}

\begin{abstract}
This study aimed to find out the differences in the earnings management practice based on the company life cycle (growth, mature, and stagnant). The samples of this study consists of 224 companies in all sectors except the financial and banking, which were listed in Indonesia Stock Exchange (IDX) during 2010-2012. This study used a Kruskal Wallis test to examine whether there were differences the earnings management practice between each level of the life cycle. The results of the study showed that there were no differences in earnings management practice at each level of the life cycle. Afterward, the earnings management practices between growth and mature level, and between mature, and stagnant level are compared. The result showed that there was a significant difference between the earnings management practice by the companies in the growth and mature level, but there was no significant difference in earnings management practice by the companies in mature and stagnant level.
\end{abstract}

Keywords: earnings management, discretionary accruals, life cycle

\section{PENDAHULUAN}

Laporan keuangan menjadi sarana bagi perusahaan untuk menyampaikan informasi keuangan mengenai pertanggungjawaban pihak manajemen terhadap pemenuhan kebutuhan pihak-pihak eksternal, melalui penyajian informasi kinerja perusahaan (Wahyono et al., 2013). Secara tidak langsung manajemen diharuskan menghasilkan laporan keuangan yang baik untuk meningkatkan kepercayaan masyarakat dan juga investor. Menurut Halim et al. (2005), penyusunan laporan keuangan menggunakan dasar akrual karena lebih rasional dan adil dalam mencerminkan kondisi keuangan perusahaan secara riil. Penggunaan dasar akrual dapat memberikan keleluasaan kepada pihak manajemen dalam memilih metode akuntansi selama tidak menyimpang dari aturan Standar Akuntansi Keuangan yang berlaku. Laporan keuangan yang baik dapat dilihat dari besar dan tidak adanya 
fluktuasi laba di dalam perusahaan tersebut. Untuk mendapatkan laba yang besar dan stabil, maka manajemen seringkali melakukan earnings management untuk bisa mendapatkan laporan keuangan yang baik.

Menurut Kim et al. (2003) serta Yan (2006) dalam Hastuti dan Hutama (2010), earnings management dapat dilakukan pada perusahaan yang berada pada tahap growth (pertumbuhan), tahap mature (matang) sampai dengan tahap stagnant (stabil). Earnings management perusahaan yang berada pada tahap stagnant lebih kecil daripada perusahaan yang berada pada tahap mature.

Penelitian ini mereplikasi dari tulisan Hastuti (2010) dengan menggunakan objek penelitian semua perusahaan yang terdaftar di BEI kecuali perusahaan keuangan dan perbankan. Penelitian sebelumnya hanya meneliti perusahaan pemanufakturan, sehingga perlu dibuktikan apakah hasil penelitian akan berbeda apabila menggunakan semua jenis perusahaan yang terdaftar di BEI kecuali perusahaan keuangan dan perbankan.

\section{TELAAH PUSTAKA}

\section{Earnings Management}

Menurut Adrian dan Restuti (2011) earnings management adalah pemilihan kebijakan akuntansi oleh manajer untuk mencapai tujuan khusus atau sebagai intervensi dengan maksud tertentu terhadap proses pelaporan keuangan dengan sengaja untuk memperoleh keuntungan pribadi. Earnings management muncul akibat adanya teori keagenan dan teori akuntansi positif. Teori keagenan menyatakan bahwa praktik manajemen laba dipengaruhi oleh konflik kepentingan antara manajemen (agent) dan pemilik (principal) yang timbul karena adanya keinginan untuk memaksimalkan kemakmuran masing-masing. Teori akuntansi positif didasarkan pada adanya dalil bahwa manajer, pemegang saham dan aparat pengatur adalah rasional dan mereka berusaha untuk memaksimalkan kegunaan mereka, yang secara langsung berhubungan dengan kompensasi serta kesejahteraan mereka (Prabayanti dan Yasa 2010). Apabila laporan keuangan yang dihasilkan oleh manajemen buruk (laba yang rendah), maka akan menurunkan harga saham. Hal ini akan sangat merugikan para pemegang saham dan mereka akan menganggap kinerja dari manajemen perusahaan buruk. Akibat dari kondisi ini adalah pemegang saham akan mengganti manajemen tersebut. Dalam rangka menyelaraskan tujuan dari pemegang saham dan manajemen, maka dilakukanlah earnings management yang sebenarnya merugikan pemegang saham.

Adrian dan Restuti (2011) menyatakan bahwa identifikasi earnings management dilakukan dengan mengeluarkan komponen kas dari model akuntansi untuk menghitung dan menentukan besarnya komponen akrual yang diperoleh perusahaan selama satu periode tertentu. Kemudian memisahkan komponen akrual 
tersebut menjadi dua komponen utama yaitu discretionary accruals dan non discrtionary accruals. Discretionary accruals merupakan komponen akrual hasil rekayasa manajerial dengan memanfaatkan kebebasan dan keleluasaan dalam estimasi dan pemakaian standar akuntansi. Non discretionary accruals merupakan komponen akrual yang diperoleh secara alamiah dari dasar pencatatan akrual dengan mengikuti standar akuntansi yang diterima secara umum.

\section{Life Cycle Perusahaan}

Menurut Schori dan Garee (1998) dalam Hastuti (2010), perusahaan memiliki life cycle seperti halnya dengan produk, yaitu introduction, growth, mature dan decline. Pada saat introduction, perusahaan digambarkan seperti anak kecil yang baru belajar berjalan. Perusahaan baru diperkenalkan sebagai bisnis yang kecil. Sebagian besar cepat gagal karena eksekutif tidak memahami kebutuhan pasar dan tidak mengetahui bagaimana memenuhi kebutuhan tersebut serta tidak memiliki bakat pengusaha. Tetapi jika perusahaan tersebut sukses, penjualan mulai bertumbuh.

Tahap yang kedua adalah growth, dimana perusahaan digambarkan seperti anak remaja yang belum dewasa. Pada tahap ini, perusahaan mulai memenuhi kebutuhan pasar dan pertumbuhannya cepat. Pertumbuhan ini merupakan hasil dari pemenuhan kebutuhan pasar yang lebih baik dari kompetisi dan semangat usaha dari pendiri perusahaan tersebut.

Tahap yang ketiga adalah mature, dimana perusahaan digambarkan seperti seorang dewasa. Perusahaan memasuki tahap dimana para manajernya mulai profesional. Tetapi umur perusahaan tidak panjang lagi dan mengarah pada tahap akhir life cycle perusahaan. Ada beberapa perusahaan yang tetap berada pada tahap ini untuk jangka waktu yang panjang tapi ada juga yang mengarah pada kebangkrutan. Pada tahap setelah mature, ada perusahaan yang tidak memasuki tahap decline tetapi tetap berada pada posisi stabil (stagnant).

\section{Kerangka Pemikiran dan Pengembangan Hipotesis}

Perusahaan mengalami tahapan selama hidupnya (life cycle) yaitu dimulai dengan start-up, growth, mature dan stagnant. Ketika berada pada tahap growth, perusahaan membutuhan dana yang besar dari para investor untuk perkembangan dan kemajuan usahanya. Hal ini menyebabkan manajemen harus membuat laporan keuangan sebaik mungkin yang salah satunya dapat dilihat dari laba yang tinggi. Namun hal ini mengalami kendala yang disebabkan perusahaan masih kurang memiliki pengalaman dan masih minimnya kepercayaan investor untuk berinvestasi. Oleh karena itu earnings management biasanya dilakukan secara besar-besaran pada tahap ini. Menurut Scott (2000) dalam Restuningdiah (2011) menyatakan bahwa terdapat empat pola yang dilakukan manajemen untuk melakukan manajemen laba, yaitu taking a bath, income minimization, income maximization dan income smoothing. Ketika perusahaan berada pada tahap start-up, manajemen melakukan perkenalan terhadap masyarakat. Cash flow yang dimiliki perusahaan pada tahap ini 
masih rendah sehingga manajemen melakukan earnings management. Ketika perusahaan sudah mencapai tahap growth, cash flow yang dimiliki perusahaan sudah tinggi. Namun perusahaan harus menarik investor untuk mengembangkan bisnisnya. Salah satu upaya yang dilakukan manajemen untuk menarik investor adalah dengan melakukan earnings management agar laba perusahaan tinggi. Setelah mencapai tahap mature, perusahaan melakukan persaingan pasar dengan perusahaan sejenis lainnya sehingga laba cenderung mengalami penurunan. Pada saat itulah manajemen melakukan salah satu bagian dari earnings management yaitu income smoothing (perataan laba), agar laba menjadi stabil dan laporan keuangan menjadi bagus. Sedangkan pada tahap stagnant perusahaan sudah stabil dan fluktuasi laba tidak signifikan, sehingga kecil kemungkinan bagi manajemen untuk melakukan earnings management.

Menurut Hastuti (2010) earnings management lebih kecil dilakukan pada perusahaan yang berada pada tahap stagnant dibandingkan dengan perusahaan yang berada pada tahap mature, karena pada tahap stagnant perusahaan telah memiliki pengendalian internal yang canggih dan auditor internal lebih kompeten dibandingkan pada tahap mature. Untuk itu disusun hipotesis sebagai berikut.

H1: Terdapat earnings management yang semakin rendah seiring dengan perubahan life cycle perusahaan dari tahap growth, mature sampai dengan stagnant.

\section{METODA PENELITIAN}

\section{Populasi dan Sampel}

Populasi dari penelitian ini adalah seluruh perusahaan kecuali perusahaan keuangan dan perbankan yang terdaftar di Bursa Efek Indonesia periode 2010-2012. Teknik pengambilan sampel dilakukan dengan purposive sampling agar sampel yang diambil sesuai dengan kriteria yang telah ditetapkan, yaitu sebagai berikut.

1. Perusahaan mempublikasikan laporan keuangan tahunan untuk periode 31 Desember 2010 sampai dengan 31 Desember 2012.

2. Memiliki data yang lengkap untuk mendeteksi manajemen laba.

3. Memiliki data yang lengkap untuk pengklasifikasian life cycle.

4. Tidak termasuk perusahaan keuangan dan perbankan.

Berdasarkan kriteria pemilihan sampel, diperoleh sampel sebanyak 298 perusahaan dari total 381 perusahaan yang terdaftar di BEI pada 31 Desember 2012. Namun berdasarkan pengklasifikasian life cycle menurut Anthony dan Ramesh (1992), dari 298 perusahaan tersebut hanya sebanyak 224 perusahaan yang dapat diklasifikasikan ke dalam tahap growth, mature dan stagnant. Sisanya sebanyak 74 perusahaan tidak termasuk dalam pengklasifikasian yang ditunjukkan oleh Tabel 1. Sejumlah 87 perusahaan yang masuk dalam tahap growth, 77 perusahaan termasuk 
dalam tahap mature dan sebanyak 60 perusahaan yang termasuk dalam tahap stagnant yang dapat dilihat pada Tabel 1.

Tabel 1

Sampel Penelitian

\begin{tabular}{lc}
\hline Perusahaan dengan data lengkap sesuai dengan kriteria pemilihan sampel & 298 \\
Perusahaan yang tidak termasuk ke dalam tahap pengklasifikasian life cycle & 74 \\
Perusahaan yang termasuk ke dalam tahap pengklasifikasian life cycle & $\mathbf{2 2 4}$ \\
\hline Tahap Growth & 87 \\
Tahap Mature & 77 \\
Tahap Stagnant & 60 \\
Total & $\mathbf{2 2 4}$ \\
\hline
\end{tabular}

Sumber: data sekunder diolah

\section{Pengukuran Life Cycle Perusahaan}

Perusahaan diklasifikasikan ke dalam tahap growth, mature dan stagnant dengan kriteria dividend payout (DP), sales growth (SG), capital expenditure value (CEV) dan umur perusahaan (AGE).

Tabel 2

Ekspetasi empat variabel pada setiap tahap life cycle perusahaan

\begin{tabular}{lllll}
\hline \multirow{2}{*}{$\begin{array}{c}\text { Tahap Life } \\
\text { Cycle }\end{array}$} & \multicolumn{4}{c}{ Variabel Klasifikasi Life Cycle } \\
\cline { 2 - 5 } & \multicolumn{1}{c}{$\boldsymbol{D P}$} & \multicolumn{1}{c}{ SG } & \multicolumn{1}{c}{ CEV } & AGE \\
\hline Growth & Low & High & High & Young \\
Mature & Medium & Medium & Medium & Adult \\
Stagnant & High & Low & Low & Old \\
\hline Sumber: Anthony dan Ramesh (1992) & &
\end{tabular}

Tahapan growth memiliki tanda apabila suatu tahun perusahaan berada pada kuintil tertinggi (kuintil pertama) dari gabungan skor peringkat pertumbuhan penjualan dan capital expenditure dan berada pada kuintil terendah (kuintil pertama) dari gabungan skor peringkat dividend payout dan umur perusahaan. Tahap mature memiliki tanda apabila suatu tahun-perusahaan berada pada kuintil tengah dari gabungan skor peringkat pertumbuhan penjualan dan capital expenditure, berada pada kuintil tengah skor peringkat dividend payout dan berada pada kuintil tengah skor peringkat umur perusahaan. Tahap stagnant memiliki tanda apabila suatu tahun berada pada kuintil terendah (kuintil ke empat) gabungan skor peringkat pertumbuhan penjualan dan capital expenditure, berada pada kuintil tertinggi (kuintil ke empat) dari skor peringkat dividend payout, dan berada pada kuintil tertinggi (kuintil ke empat) dari skor peringkat umur perusahaan. 
Menurut Hastuti (2010) masing-masing variabel dihitung dengan cara berikut ini:

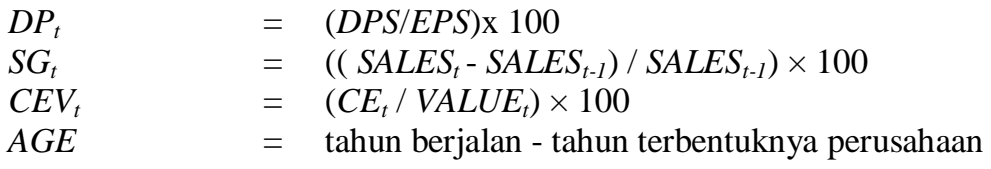

Keterangan:

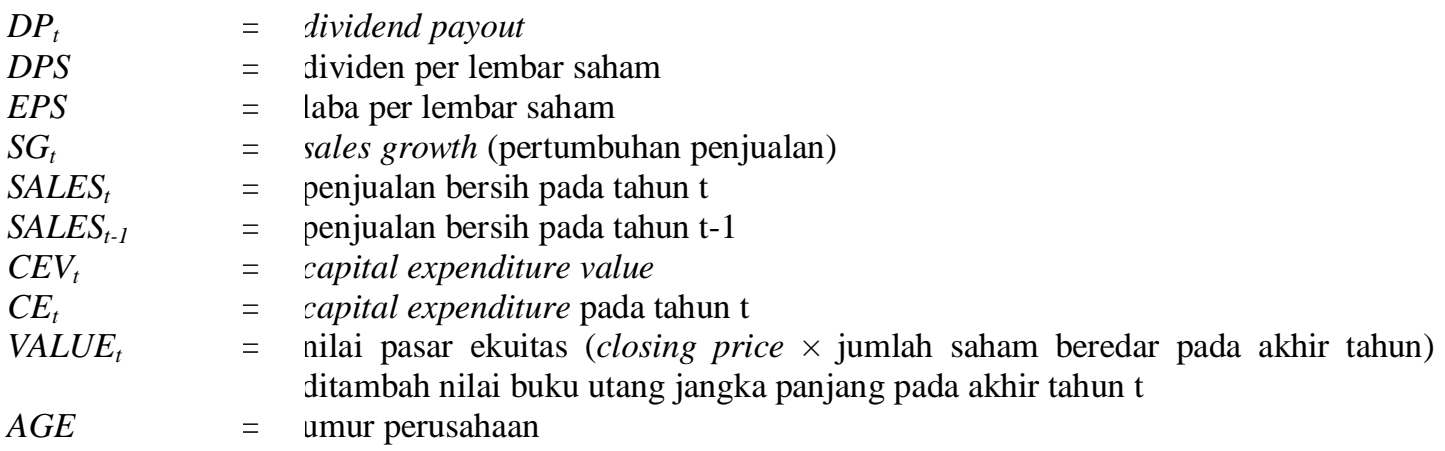

\section{Earnings Management}

Menurut Ujiyantho dan Pramuka (2007), manajemen laba dilakukan oleh manajer pada faktor-faktor fundamental perusahaan, yaitu dengan intervensi pada penyusunan laporan keuangan berdasarkan akuntansi akrual. Dechow et al. dalam Ujiyantho dan Pramuka (2007) menyebutkan bahwa penggunaan discretionary accruals sebagai proksi manajemen laba dihitung dengan menggunakan modified Jones' model karena model ini dianggap lebih baik di antara model lain untuk mengukur manajemen laba. Model tersebut dituliskan sebagai berikut ini:

Total accruals sesungguhnya $(T A C)=$ NIit - Cfit 1

Keterangan:

NIit $\quad=$ laba bersih (net income) perusahaan i pada periode $\mathrm{t}$

CFit $\quad=$ arus kas operasi (cash flow of operation) perusahaan i pada periode $\mathrm{t}$

Total accruals yang diestimasi dengan persamaan regresi OLS (Ordinary Least Square) adalah:

TACt/TAt $1=(\beta) 1(1 /$ TAt -1$)+(\beta) 2(\Delta$ SALt/TAt -1$)+(\beta) 3($ PPEt/TAt -1$)+e$ 2

Keterangan:

TACt = total accruals dalam periode $\mathrm{t}$

TAt-1 $=$ total asset periode $\mathrm{t}-1$

$(\Delta) \mathrm{SAL} \quad=$ perubahan pendapatan atau penjualan bersih dalam periode $\mathrm{t}$

PPEt $\quad=$ property, plan, and equipment periode $\mathrm{t}$

$\beta \quad=$ koefisien regresi

Dengan menggunakan koefisien regresi di atas nilai non discretionary accruals (NDA) dapat dihitung dengan rumus:

NDTACt $\quad=(\beta) 1(1 /$ TAt-1) $+(\beta) 2[(\triangle S A L t-\triangle R E C t) / T A t-1]+(\beta) 3(P P E t / T A t-1)+e \ldots \ldots \ldots \ldots . . .3$ 
Keterangan:

$(\triangle) R E C t \quad=$ perubahan piutang usaha dalam periode $\mathrm{t}$

$\beta \quad=$ fitted coefficient yang diperoleh dari hasil regresi pada perhitungan total akrual

Adapun perumusan diskresioner total akrual adalah sebagai berikut:

DTACt

$=$ TACt $\mathrm{TAt}-1-\mathrm{NDTACt}$. 4

Keterangan:

DTACt = diskresioner total akrual tahun $\mathrm{t}$

TACt = total accruals tahun $\mathrm{t}$

NDTACt = non akrual diskresioner pada tahun $\mathrm{t}$

Menurut Saiful (2002) dalam Hastuti (2010), earnings management terjadi jika discretionary accruals $(D A C)>0$. Untuk menguji apakah nilai $D A C>0$ atau tidak, digunakan model statistik parametrik one sample t test.

Untuk menguji hipotesis dilakukan langkah-langkah analisis sebagai berikut (Hastuti dan Hutama 2010).

1. Mengelompokkan semua perusahaan yang mempunyai discretionary accruals yang lebih dari nol.

2. Mengelompokkan hasil data menjadi tiga kelompok, yaitu life cycle perusahaan dikelompokkan ke dalam kelompok growth, mature dan stagnant.

3. Menghitung jumlah perusahaan yang mempunyai discretionary accruals positif untuk masing-masing kelompok analisis.

4. Menguji normalitas data dengan one sample Kolmogorov-Smirnov test (untuk menentukan alat analisis yang digunakan, parametrik atau non parametrik).

5. Pengujian statistik deskriptif. Jika berdistribusi normal, maka pengujian hipotesis dilakukan dengan menggunakan uji statistik $\mathrm{F}$ atau ANOVA. Sedangkan jika tidak berdistribusi normal, menggunakan uji Kruskal Wallis dan uji median untuk ketiga kelompok (growth, mature dan stagnant) serta uji Mann-Whitney untuk kedua kelompok (growth dan mature, serta mature dan stagnant) (Santoso 2001 dalam Hastuti dan Hutama 2010).

6. Membandingkan nilai rata-rata masing-masing kelompok perusahaan.

7. Menyimpulkan hasil analisis. Dasar pengambilan keputusan dalam pengujian ini adalah jika probabilitas >0,05 maka tidak ada perbedaan dan sebaliknya, jika probabilitas $<0,05$ berarti ada perbedaan antara ketiga kelompok perusahaan.

\section{HASIL ANALISIS DAN PEMBAHASAN}

\section{Statistik Deskriptif}

Berdasarkan statistik deskriptif pada Tabel 3 diatas, dapat dilihat bahwa perusahaan yang berada pada tahap growth sebanyak 261 perusahaan, dengan DAC terendah sebesar -1,12705, tertinggi sebesar 1,19864 dan rata-rata sebesar -0,057936. Perusahaan yang berada pada tahap mature sebanyak 231 perusahaan, dengan $D A C$ 
terendah sebesar -1,31103, tertinggi sebesar 0,87419 dan rata-rata sebesar -0,012505. Perusahaan yang berada pada tahap stagnant sebanyak 180 perusahaan, dengan DAC terendah sebesar -1,00156, tertinggi sebesar 0,68340 dan rata-rata sebesar -0,024855.

Tabel 3

Statistik Deskriptif Variabel Discretionary Accrual

\begin{tabular}{lccccc}
\hline Life Cycle & $\boldsymbol{N}$ & Minimum & Maximum & Mean & Std. Deviation \\
\hline Growth & 261 & $-1,12705$ & 1,19864 & $-0,057936$ & 0,2879 \\
Mature & 231 & $-1,31103$ & 0,87419 & $-0,012505$ & 0,2761 \\
Stagnant & 180 & $-1,00156$ & 0,68340 & $-0,024855$ & 0,2252 \\
\hline Sumber: & & & &
\end{tabular}

\section{Uji Distribusi Normal}

Untuk mendeteksi normalitas data dapat dilakukan dengan uji KolmogorovSmirnov (Ghozali dan Imam 2011). Berdasarkan olah data yang dilakukan, pada tahap growth signifikansi yang diperoleh sebesar 0,259 sehingga disimpulkan bahwa data berdistribusi normal. Sedangkan pada tahap mature dan stagnant diperoleh nilai signifikansi sebesar 0,008 dan 0,010 maka dapat dikatakan data tidak berdistribusi normal.

\section{Pengujian Hipotesis}

One sample $t$ test digunakan dalam penelitian ini untuk melihat apakah discretionary accruals perusahaan lebih dari nol. Apabila signifikansi lebih kecil dari alfa sebesar 0,05 maka dapat dikatakan bahwa $D A C>0$. Hasil olah data yang dilakukan peneliti menunjukkan bahwa signifikansi yang diperoleh adalah sebesar $0,001<0,05$, sehingga disimpulkan bahwa discretionary accruals dari sampel perusahaan yang dipilih lebih besar dari nol. Hasil dari one-sample t test dapat dilihat pada Tabel 4.

Tabel 4

Hasil Pengujian Statistik

\begin{tabular}{lr}
\hline Indikator & \multicolumn{1}{c}{ Nilai } \\
\hline One Sample t Test & $-3,228$ \\
$t$ & 0,001 \\
Signifikansi 2 sisi & \\
\hline Kruskal Wallis & 316,27 \\
Mean rank (growth) & 357,28 \\
Mean rank (mature) & 339,18 \\
Mean rank (stagnant) & 0,063 \\
Signifikansi & \\
\hline Uji Median & 0,00388 \\
Median & 0,015 \\
Signifikansi & \\
\hline Sumber: hasil uji statistik dengan SPSS &
\end{tabular}

Setelah lolos uji one-sample t test, langkah selanjutnya adalah uji Kruskal Wallis. Menurut Hastuti (2010), uji Kruskal Wallis digunakan untuk menguji apakah ada perbedaan secara signifikan diantara ketiga populasi (growth, mature dan 
stagnant). Hasil dari uji Kruskal Wallis dapat dilihat pada Tabel 4, sedangkan uji Median digunakan sebagai pelengkap dari uji Kruskal Wallis dan untuk melihat apakah nilai tengah dari ketiga populasi sama atau tidak. Hasil uji Median dapat dilihat pada Tabel 4.

Dari hasil uji Kruskal Wallis pada Tabel 4 dapat dilihat bahwa nilai signifikansi sebesar 0,063 (lebih besar dari alfa), maka dapat dikatakan bahwa ratarata discretionary accrrual dari ketiga populasi (growth, mature dan stagnant) adalah sama. Sedangkan hasil uji median menunjukkan nilai signifikansi sebesar 0,015, sehingga dapat disimpulkan bahwa minimal salah satu dari ketiga tahap (growth, mature dan stagnant) memiliki nilai tengah discretionary accruals yang berbeda. Selanjutnya dilakukan uji Mann-Whitney untuk melihat perbedaan antara perusahaan yang berada di tahap growth dan mature, dan tahap mature dan stagnant.

-Hasil dari pengujian yang telah dilakukan dengan menggunakan uji beda menunjukkan nilai signifikansi sebesar 0,063 yang berarti bahwa tidak terdapat perbedaan rata-rata discretionary accruals yang dilakukan oleh perusahaan yang berada baik pada tahap growth, mature maupun stagnant. Selanjutnya hipotesis awal yang menyatakan bahwa terdapat earnings management yang semakin rendah seiring dengan perubahan life cycle perusahaan dari tahap growth, mature sampai dengan stagnant tidak didukung. Hal tersebut bisa dilihat dari rata-rata discretionary accruals untuk perusahaan yang berada pada tahap growth sebesar 316,27, kemudian untuk perusahaan yang berada pada tahap mature sebesar 357,28 dan perusahaan yang berada pada tahap stagnant sebesar 339,18.

Tabel 5

Earnings Management di Tiap Tahap Life Cycle

\begin{tabular}{lc}
\hline Life Cycle & Earnings Management \\
\hline Growth & Rendah \\
Mature & Tinggi \\
Stagnant & Sedang \\
\hline Sumber: hasil penelitian &
\end{tabular}

Dari hasil uji beda yang telah dilakukan, gambaran hasil penelitian seperti yang ditunjukkan oleh Tabel 5. Earnings management dilakukan paling tinggi ketika perusahaan berada pada tahap mature. Hal ini dilakukan oleh manajemen untuk mempertahankan investor agar tetap berinvestasi, sehingga perusahaan yang berada pada tahap ini melakukan earnings management yang paling tinggi (rata-rata discretionary accruals paling tinggi). Menurut Diah (2009) perusahaan yang berada pada tingkat maturity mengalami puncak penjualan (tetapi pertumbuhan penjualannya di bawah tahap start-up dan growth), sehingga mengalami penurunan laba akibat kompetisi harga. Tingkat likuidasi kelompok ini juga tinggi karena kelangkaan kesempatan investasi yang bagus di dalam perusahaan. Ketika pada tahap stagnant, perilaku earnings management dilakukan pada tingkat sedang karena pengendalian internal yang lebih baik dibandingkan ketika perusahaan berada di 
tahap mature. Pada tahap growth perilaku earnings management yang dilakukan paling rendah. Hal ini dikarenakan perusahaan berada pada tingkat penjualan yang tinggi dan juga mulai melakukan diversifikasi produk.

Nilai signifikansi dari discretionary accruals (DAC) adalah sebesar 0,001, oleh karena itu dapat diambil kesimpulan bahwa perusahaan yang diambil sebagai sampel dalam penelitian ini melakukan earnings management. Namun penelitian ini tidak dapat membuktikan bahwa terdapat perbedaan perilaku earnings management berdasarkan pada life cycle perusahaan. Hal ini konsisten dengan penelitian Hastuti dan Hutama (2010), serta penelitian Myers dan Skinner dalam Dechow dan Skinner (2000) bahwa sulit untuk memisahkan praktik earnings management dari penggunaan kebijakan akuntansi yang sah. Sebagai tambahan analisis, maka dilakukan uji beda diantara tahap growth dengan mature dan mature dengan stagnant.

Tabel 6

Hasil Pengujian Lanjutan dengan Uji Mann Whitney

\begin{tabular}{lcc}
\hline \multicolumn{1}{c}{ Indikator } & \multicolumn{2}{c}{ Nilai } \\
& Growth dan Mature & Mature dan Stagnant \\
\hline Mann-Whitney & 26673 & 19463 \\
Wilcoxon & 60864 & 35753 \\
$Z$ & $-2,206$ & $-1,111$ \\
Signifikansi 2 sisi & 0,027 & 0,267 \\
\hline \multicolumn{2}{l}{ Sumber : hasil uji statistik dengan SPSS }
\end{tabular}

Hasil uji lanjutan untuk tahap growth dan mature memberikan nilai signifikansi 0,027 yang berarti terdapat perbedaan discretionary accruals secara signifikan untuk kedua tahap ini. Hal ini disebabkan ketika berada pada tahap growth, perusahaan membayar dividen yang rendah atau bahkan tidak membayar dividen sama sekali, sehingga perusahaan cenderung untuk tidak melakukan earnings management. Untuk perusahaan yang berada pada tahap mature, pengendalian internalnya sudah lebih baik dibandingkan dengan tahap growth, namun perusahaan sudah tidak lagi memiliki kesempatan investasi yang bagus dan tingkat likuidasi yang tinggi. Hal ini mengakibatkan perusahaan melakukan earnings management yang tinggi di tahap ini. Pada tahap mature dengan stagnant, diperoleh hasil 0,267 yang berarti tidak terdapat perbedaan discretionary accruals secara signifikan pada tahap mature dan stagnant. Hal ini dikarenakan ketika perusahaan berada pada tahap stagnant, perusahaan memiliki karakteristik yang hampir sama dengan perusahaan yang berada pada tahap mature walaupun memiliki pengendalian internal yang lebih baik. 


\section{SIMPULAN}

Penelitian ini dilakukan untuk membuktikan apakah terdapat earnings management yang semakin rendah seiring dengan perubahan life cycle perusahaan dari tahap growth, mature sampai dengan stagnant. Hasil penelitian ini tidak dapat membuktikan bahwa perilaku earnings management yang semakin rendah seiring dengan perubahan life cycle perusahaan dikarenakan untuk mempertahankan investor tetap berinvestasi maka manajemen melakukan earnings management besar-besaran pada tahap mature, sehingga perusahaan yang berada pada tahap ini melakukan earnings management yang paling tinggi (rata-rata discretionary accruals paling tinggi). Sedangkan perusahaan yang berada pada tahap growth perusahaan melakukan earnings management paling rendah, karena perusahaan berada pada tingkat penjualan yang tinggi dan juga mulai melakukan diversifikasi produk. Untuk itu peneliti melakukan uji tambahan untuk melihat perbedaan perilaku earnings mangement diantara tahap growth dengan mature serta mature dengan stagnant. Hasil dari uji tersebut menunjukkan bahwa terdapat perbedaan yang signifikan pada perilaku earnings management di tahap growth dan mature, tetapi tidak terdapat perbedaan yang signifikan perilaku earnings management di tahap mature dengan stagnant.

Implikasi hasil penelitian ini secara teoretis adalah menambahkan referensi mengenai penelitian earnings management terkait dengan siklus hidup perusahaan. Implikasi praktis bagi investor, agar dapat mempertimbangkan untuk melihat siklus hidup perusahaan, sedang berada di tahap apa, sehingga lebih bijak dalam menilai dan menggunakan laporan keuangan perusahaan.

Keterbatasan dalam penelitian ini adalah hanya menggunakan satu model pengklasifikasian life cycle milik Anthony dan Ramesh (1992), yang hanya membagi perusahaan ke dalam tiga tahap, yaitu growth, mature dan stagnant. Hastuti dan Hutama (2010) menyebutkan bahwa model ini memiliki kelemahan yaitu ada satu variabel yang sangat lemah pengaruhnya dalam pengklasifikasian life cycle perusahaan yaitu variabel capital expenditure value (CEV) karena perbedaan antar perusahaan dalam $C E V$ tampak lebih berkaitan dengan fungsi produksi perusahaan daripada life cycle perusahaan. Keterbatasan selanjutnya adalah penelitian ini hanya melihat apakah perusahaan yang diambil sebagai sampel melakukan earnings management atau tidak, dan tidak melihat apakah perusahaan tersebut menaikkan atau menurunkan laba. Penulis menyarankan kepada peneliti selanjutnya untuk menggunakan model pengklasifikasian selain Anthony dan Ramesh (1992) yang membagi life cycle perusahaan ke dalam tahap yang lebih detail (empat sampai lima tahap), meminimalkan data yang tidak terklasifikasi serta mengambil sampel perusahaan dari keuangan dan perbankan. 


\section{DAFTAR PUSTAKA}

Adrian, M. A., dan M. I. Restuti, M. 2011. Pengaruh corporate governance terhadap manajemen laba di industri perbankan industri. Transformatif. Vol.1 No.1: 16-30.

Anthony, J. H., dan K. Ramesh. 1992. Association between accounting performance measures and stock prices: a test of the life cycle hypothesis. Journal of Accounting and Economics. Vol.15: 203-227.

Dechow, P. M., dan D. J. Skinner. 2000. Earning management: reconciling the views of accounting academics, practitioners, and regulators. Accounting Horizons. Vol.14 No.2: 235-250.

Diah, U. P. 2009. Relevansi nilai laba dan arus kas studi: siklus hidup perusahaan (metode cash flow patterns). Skripsi. Surakarta: Universitas Sebelas Maret

Ghozali, I. 2011. Aplikasi Analisis Multivariate dengan Program IBM SPSS 19. Semarang: Badan Penerbit Universitas Diponegoro.

Halim, J., C. Meiden, dan R. L. Tobing. 2005. Pengaruh manajemen laba pada tingkat pengungkapan laporan keuangan pada perusahaan manufaktur yang termasuk dalam indeks LQ-45. Prosiding Simposium Nasional Akuntansi VIII.

Hastuti, Sri. 2010. The influence of companies' life cycles on earnings management behavior. The Indonesian Journal of Accounting Research. Vol.13 No.2.

Hastuti, S., dan P. S. P Hutama. 2010. Perbedaan perilaku earning management berdasarkan pada perbedaan life cycle dan ukuran perusahaan. Prosiding Simposium Nasional Akuntansi XIII.

Prabayanti, N. L. P. A., dan G. W. Yasa. 2010. Perataan laba (income smoothing) dan analisis faktor-faktor yang mempengaruhinya (studi pada perusahaan manufaktur yang terdaftar di Bursa Efek Indonesia). Available at unud.ac.id.

Ujiyantho, M. A., dan B. A. Pramuka. 2007. Mekanisme corporate governance, manajemen laba dan kinerja keuangan (studi pada perusahaan go public sektor manufaktur). Prosiding Simposium Nasional Akuntansi X.

Wahyono, R. E. S., Wahidahwati, dan A. Sunaryo. 2013. Pengaruh corporate governance pada praktik manajemen laba: studi pada industri perbankan Indonesia. Jurnal Ilmu dan Riset Akuntansi. Vol.1 No.2. 